\title{
Tandem Cycloaddition-Cycloreversion of 2-pyrone and 1,4-oxazinone with Acetylene - A DFT Insight
}

\author{
Padmanaban Kalpana ${ }^{1}$, Lakshminarayanan Akilandeswari ${ }^{1}$, Ponnambalam Venuvanalingam ${ }^{2, ~ * ~}$ \\ ${ }^{1}$ Department of Chemistry, Sri Sarada College for Women (Autonomous), Salem, India \\ ${ }^{2}$ School of Chemistry, Bharathidasan University, Trichirappalli, India
}

Email address:

akilchem@gmail.com (L. Akilandeswari), venuvanalingam@yahoo.com (P. Venuvanalingam)

${ }^{*}$ Corresponding author

\section{To cite this article:}

Padmanaban Kalpana, Lakshminarayanan Akilandeswari, Ponnambalam Venuvanalingam. Tandem Cycloaddition-Cycloreversion of 2pyrone and 1,4-oxazinone with Acetylene - A DFT Insight. International Journal of Pharmacy and Chemistry. Vol. 7, No. 1, 2021, pp. 13-21 . doi: $10.11648 /$ j.ijpc.20210701.13

Received: December 5, 2020; Accepted: January 18, 2021; Published: February 27, 2021

\begin{abstract}
Reaction of either 2-pyrone or 1,4-oxazinone with acetylene follows the sequence of cycloaddition cycloreversion through concerted mechanism. Transition states for both cycloaddition and cycloreversion pathways have been obtained in both the cases by modelling the reactions at B3LYP/6-31g (d) level. Cycloreversion is faster than cycloaddition in the case of 2-pyrone due to the enhancement of aromaticity resulting the product as benzene. In contrast, oxazinone has rapid cycloaddition. It is ascribed to the presence of nitrogen in this system. Removal of either $\mathrm{CO}_{2}$ or $\mathrm{HCN}$ is plausible in this mechanism to complete the reaction. Even though two pathways are feasible for cycloreversion, $\mathrm{CO}_{2}$ extrusion is more preferable than $\mathrm{HCN}$ elimination. In these two studied molecules, there is an enhancement of aromaticity up to transition states like any other pericyclic reaction and further it diminishes during cycloaddition. Further, aromaticity is specifically augmented in cycloreversion phase during $\mathrm{CO}_{2}$ elimination resulting to yield pyridine whereas competitive $\mathrm{HCN}$ elimination results in the formation of 2-pyrone which is less facile. In both the molecules the aromatic enhancement of the cycloreversion is substantiated through the study of magnetic susceptibility of the ring fragment along the reaction coordinate. Further the study also reveals the effect of halogen substituted at different carbons of 2-pyrone ring.
\end{abstract}

Keywords: Aromaticity, Cycloaddition-cycloreversion Reactin, DFT Study, Intrinsic Reaction Coordinate

\section{Introduction}

Tandem cycloaddition-cycloreversion $\quad(\mathrm{CA}-\mathrm{CR})$ is commonly known in molecules whose cycloadducts have a potential extruding group. Some of the well-known tandem reactions of this type reported in the literature include cycloaddition of a variety of alkynes to pyrimidines resulting in cycloadducts that spontaneously extrudes nitrile to form pyridines [1]. A similar nitrile expulsion has been reported with oxazoles [2]. Pyrone undergoes cycloaddition with alkene/alkyne to form a bicyclic lactone that spontaneously extrudes $\mathrm{CO}_{2}$ to form molecules with cyclohexadiene/ benzene unit. First reaction of this kind was reported by Diels and Alder in 1931 [3]. The diene and dienophile in this reaction were 5-carbomethoxy-2-pyrone and maleic anhydride respectively. Such kind of reactions have been recognized as synthetically important and useful reactions [4, 5]. Cycloadditions afford in the first instance bridged bicyclic lactones. These functionally rich bridged cycloadducts are valuable starting materials for the synthesis of highly functionalized six-membered rings found in many natural products [6-12] such as lasalocid A, rufesine, imeluteine, chrysophanol, islandicin, emodin, sendaverine, juncusol, and norketoyobirine [13-17]. Owing to their partial aromatic nature, 2-pyrones participate in Diels-Alder reactions less readily than most cyclic conjugated homodienes [18]. In general, high temperature and pressure is required for cycloadditions to take place. However, these cycloadducts are labile at such a high temperature and rapidly extrude $\mathrm{CO}_{2}$. As the cycloadducts formed from olefinic dienophiles are good source of highly funtionalized and stereochemically rich compounds ${ }^{18}$ their isolation received the attention of many chemists. It has been found that utilization of 
electronically matching partners is one of the strategies used not only for arresting the cycloreversion (loss of $\left.\mathrm{CO}_{2}\right)$ in this reaction but also has the advantage of adding to the diversity of substituents on the cycloadducts [18a,d].

Though there has been extensive experimental study on Diels-Alder cycloadditions of 2-pyrone and its derivatives with alkenes and alkynes, enough theoretical insights have not been attempted at an equal pace. Cycloaddition reaction of 2-pyrone with acetylene has been reported only at $\mathrm{HF}$ level. Therefore, the present paper intends to explore the reaction with the following questions in mind: (i) what is the effect of aromaticity in these tandem cycloadditioncycloreversion reactions? (ii) How does heteroatom (nitrogen) in 1, 4-oxazinone affect this tandem reaction (Does it accelerate or retard cycloaddition /cycloreversion)? (iii) There are two extrusible groups in the cycloadduct formed from oxazinone and acetylene reaction viz., $\mathrm{CO}_{2}$ and nitrile; which of the two is preferentially extruded? In search of these answers the reaction path of the tandem processes have been scanned. Thermochemical activation parameters and magnetic susceptibility isotropy at every point along the Intrinsic Reaction Coordinate have been computed. Another interesting aspect in this work is the variation of aromaticity in the ring fragment of the diene unit during cycloaddition and forming product ring fragment during cycloreversion. This will help to relate the perturbation occurring in the ring moiety in terms of aromaticity during the tandem process.

\section{Computational Methods}

The computations have been done using Gaussian 98 program [19] at B3LYP [20, 21]/6-31G (d) level. The magnetic susceptibility isotropy has been calculated by computing the NMR shielding tensors at B3LYP/6-311+G (2d, p) using IGAIM method [22, 23] which is a slight variation of CSGT [22-24] method. NBO calculations [25-27] have been done. The variation in magnetic susceptibility isotropy $\left(\chi_{\text {iso }}\right)$ along the reaction coordinate and has been monitored between the range $\left(-1\right.$ to $+1(\mathrm{amu})^{1 / 2}$. Bohr $)$ for both cycloaddition and cycloreversion process. Frontier orbitals of both diene and dienophiles have also been analysed. Here, apart from this the loss of the aromaticity of the parent ring during cycloaddition and the gain of aromaticity of the newly formed ring during cycloreversion has also been calculated along the reaction coordinate by retaining the desired ring moiety alone.

\section{Results and Discussion}

The scheme $1 \& 2$ explain the steps of 2-pyrone (2P) and 1,4-Oxazinone (OXZ) reacting with acetylene (Ace) respectively. From these schemes one can understand that cycloadditions take place in the first step resulting in bicyclic lactone adducts $(\mathrm{Al} \& \mathrm{~A} 2)$. In the $2 \mathrm{P}$-Ace reaction the adduct (Al) tends to eliminate $\mathrm{CO}_{2}$ to form an aromatized product. In OXZ-Ace reaction, the adduct $\mathrm{A} 2$ formed has two paths for cycloreversion; one being $\mathrm{CO}_{2}$ extrusion and another being $\mathrm{HCN}$ extrusion As similar systems have been proved to pass through a concerted path rather than the polar mechanism, the search here is restricted to concerted path only [28].

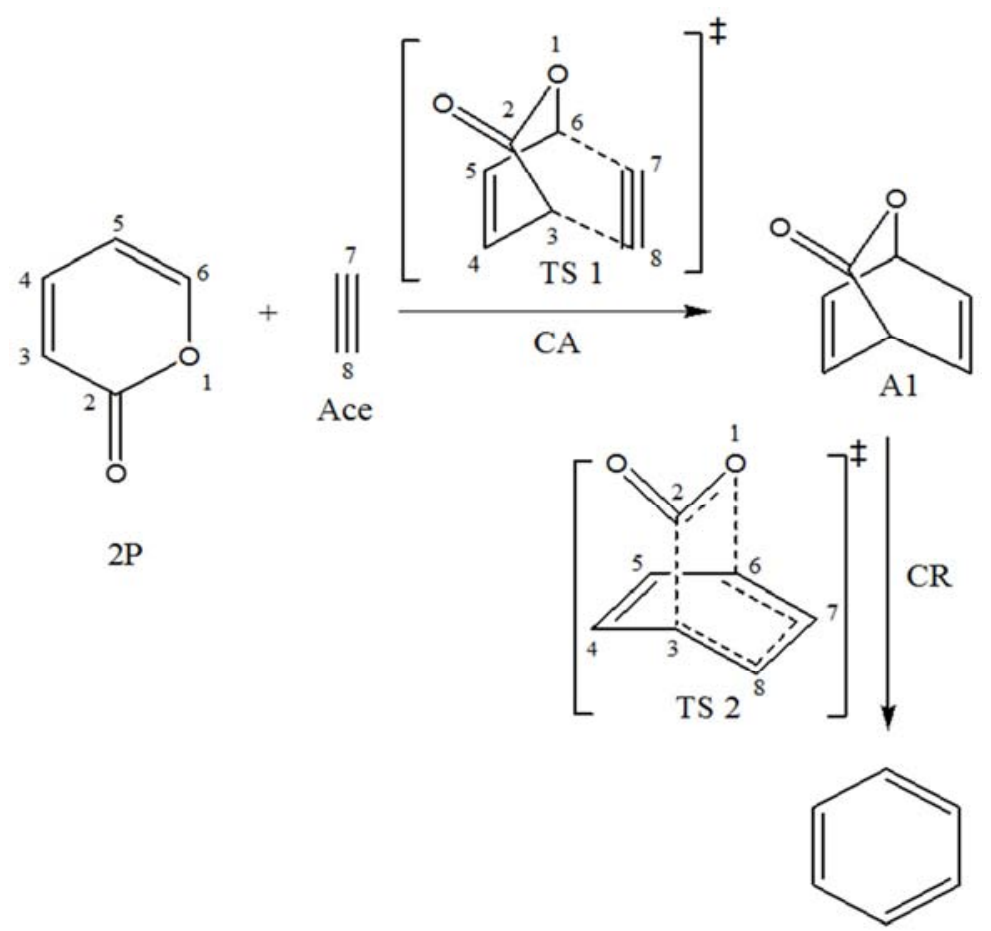




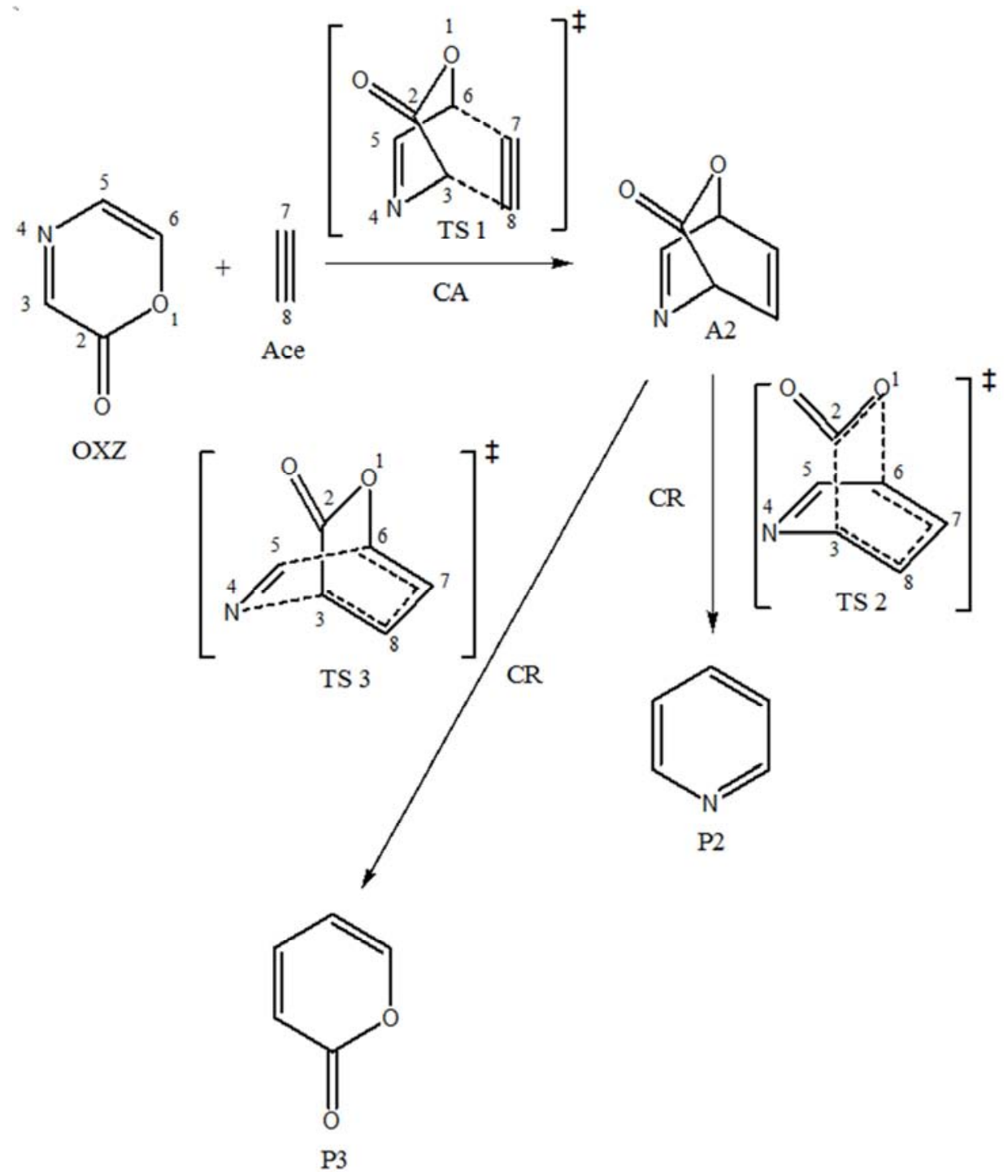

Figure 2. Reaction pathways for addition of OXZ with Ace.

\section{A. Energetics And FOE Analysis}

In the 2P-Ace reaction there are 2 transition states-TS1 \& TS2; The former is the cycloaddition TS and the latter is cycloreversion TS. The relative free energy profile for $2 \mathrm{P}$-Ace reaction and OXZ-Ace reaction are presented in Figures $3 \& 4$ respectively. Figure 3 indicates that the barrier to cycloaddition of $2 \mathrm{P}$ with Ace is $36.84 \mathrm{kcal} . \mathrm{mol}^{-1}$ while that for OXZ is 30.99 kcal.mol ${ }^{-1}$ (Figure 4). Both these barriers are much larger than the activation energy for the reaction of acetylene and cyclopentadiene $\left(\Delta E^{\sharp}=25.7 \mathrm{kcal} . \mathrm{mol}^{-1}\right)$ [27]. Such a large difference among the barriers of these embedded dienescompared to cyclopentadiene is due to the partial aromaticity of 2P and OXZ. Nitrogen atom in OXZ has in fact reduced the aromaticity of the ring consequently has its free energy of activation $5.85 \mathrm{kcal}^{\mathrm{mol}}{ }^{-1}$ lesser than $2 \mathrm{P}$-Ace reaction. The bond distances of the newly forming bonds in TSl are unequal and the observed asynchronicity is due to the asymmetry of 2P. A2 has two extrusible groups viz., $\mathrm{CO}_{2}$ and $\mathrm{HCN}$ (Figure 2 and Figure 4). A2 gives pyridine on $\mathrm{CO}_{2}$ elimination. On the other hand, on HCN extrusion, it forms 2pyrone. Energy profile presented in Figure 4 and the data presented in Table 2 show that cycloreversion by $\mathrm{CO}_{2}$ elimination is more facile than $\mathrm{HCN}$ elimination, kinetically and thermodynamically $\mathrm{CO}_{2}$ elimination yields pyridine an aromatic product, and therefore more stable, while $\mathrm{HCN}$ elimination leads to the formation of $2 \mathrm{P}$ that is partially aromatic and obviously less stable. Thus gain in aromaticityin $\mathrm{CO}_{2}$ elimination pathway reduces the activation energy greatly as reported [29]. It is noted that barrier to cycloreversion of $\mathrm{Al}$ (11.97 kcal.mol $\left.{ }^{-1}\right)$ and A2 (14.52 kcal.mol $\left.{ }^{-1}\right)$ is rather much lower and the reaction is also thermodynamically favoured to a greater extent. In both cycloreversions the cleavage of $\mathrm{C} 6-\mathrm{Ol}$ is faster than $\mathrm{C} 2-\mathrm{C} 3$. But in $\mathrm{HCN}$ elimination pathway during cycloreversion of A2 there is larger asynchronicity $(\Delta \mathrm{r}=0.31)$ with $\mathrm{N} 4-\mathrm{C} 3$ cleaving much ahead of $\mathrm{C} 5-\mathrm{C} 6$.

The relative positioning of FOs of $2 \mathrm{P}$ with acetylene and OXZ with acetylene is shown in Figure 5. It could be seen that both the cases are inverse electron demand type (IED) in which electrons move from HOMO of acetylene to LUMO of either $2 \mathrm{P}$ or OXZ. This is verified from $\mathrm{Q}_{\mathrm{CT}}$ presented in the Table 1. 


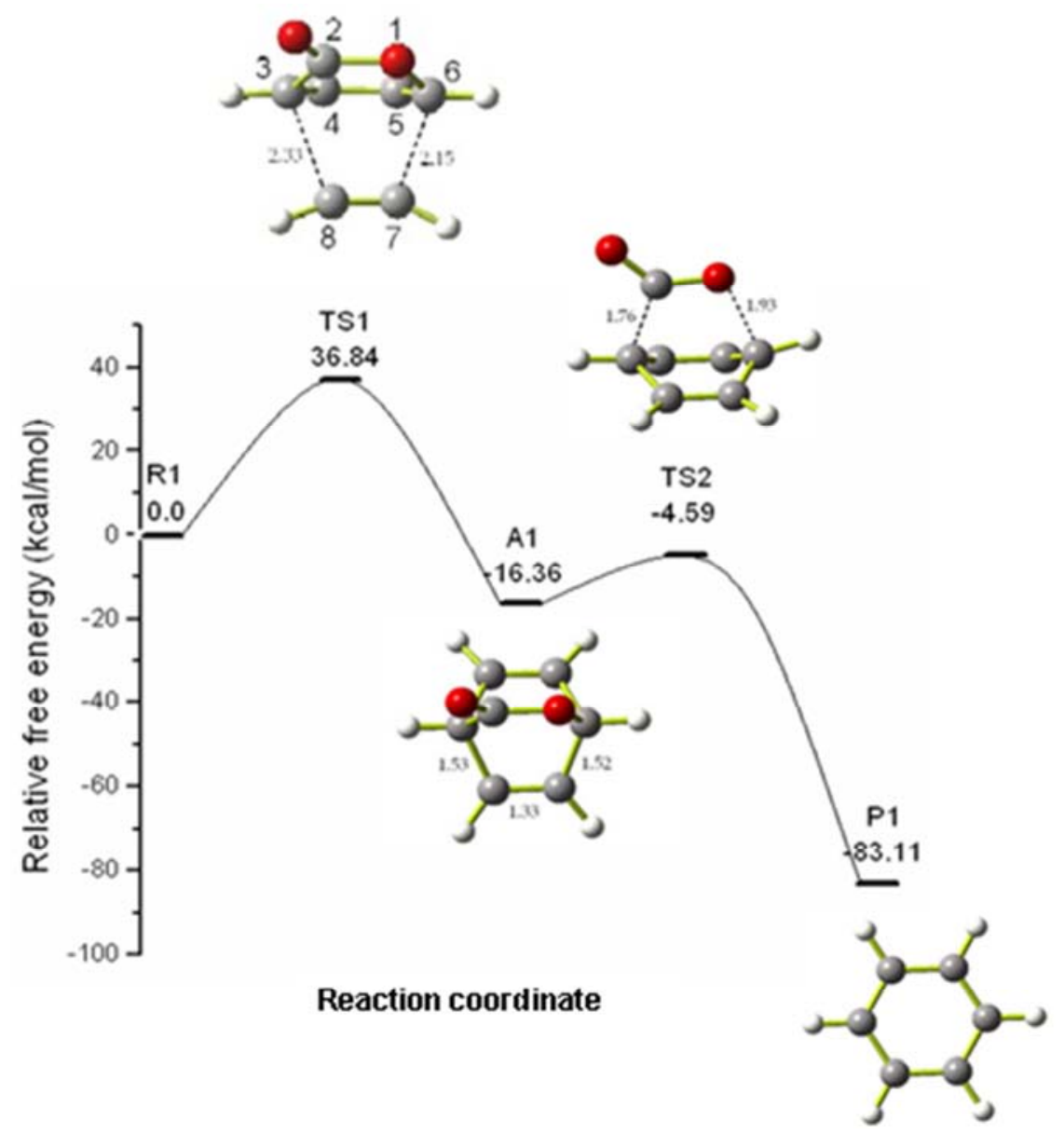

Figure 3. Schematic free energy profile of $2 P$-Ace reaction computed at B3LYP/6-31G (d) level.

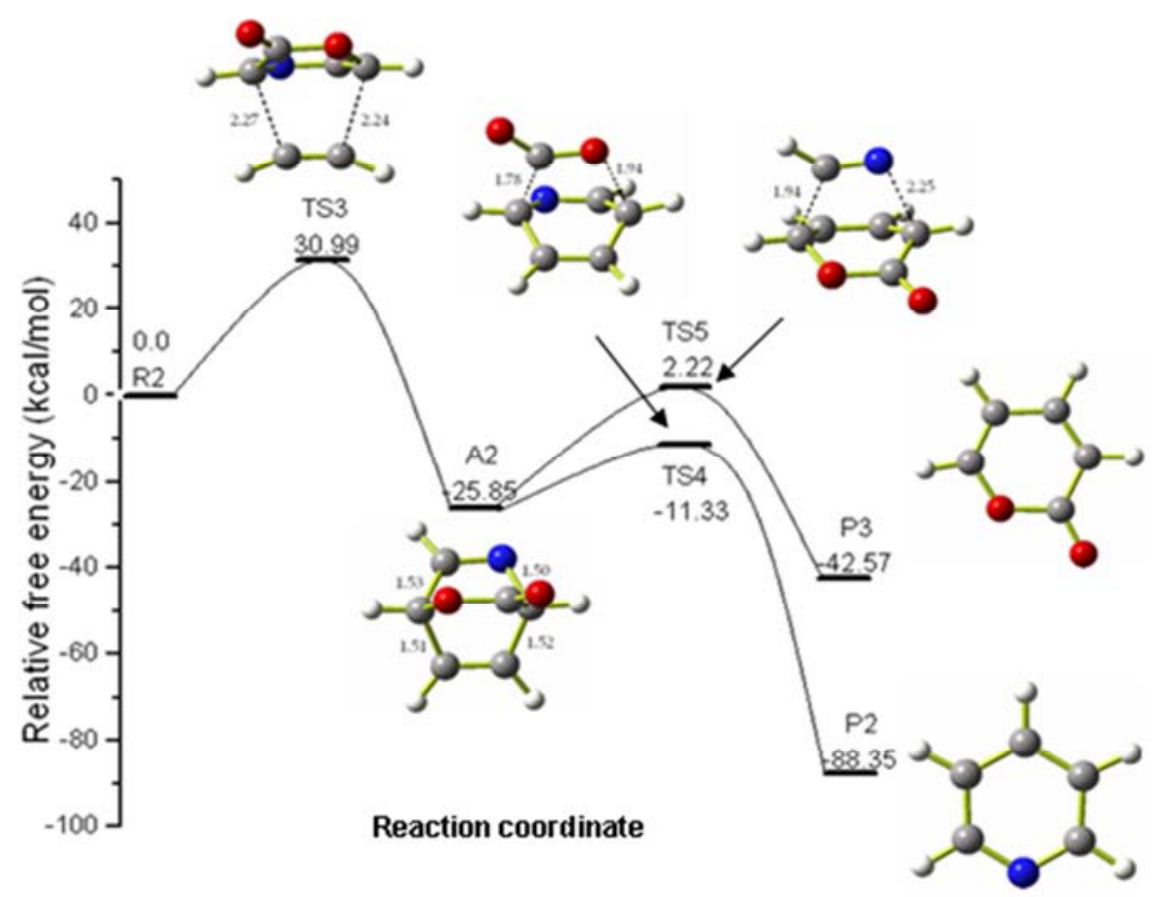

Figure 4. Schematic free energy profile of OXZ-Ace reaction computed at B3LYP/6-31G (d) level. 

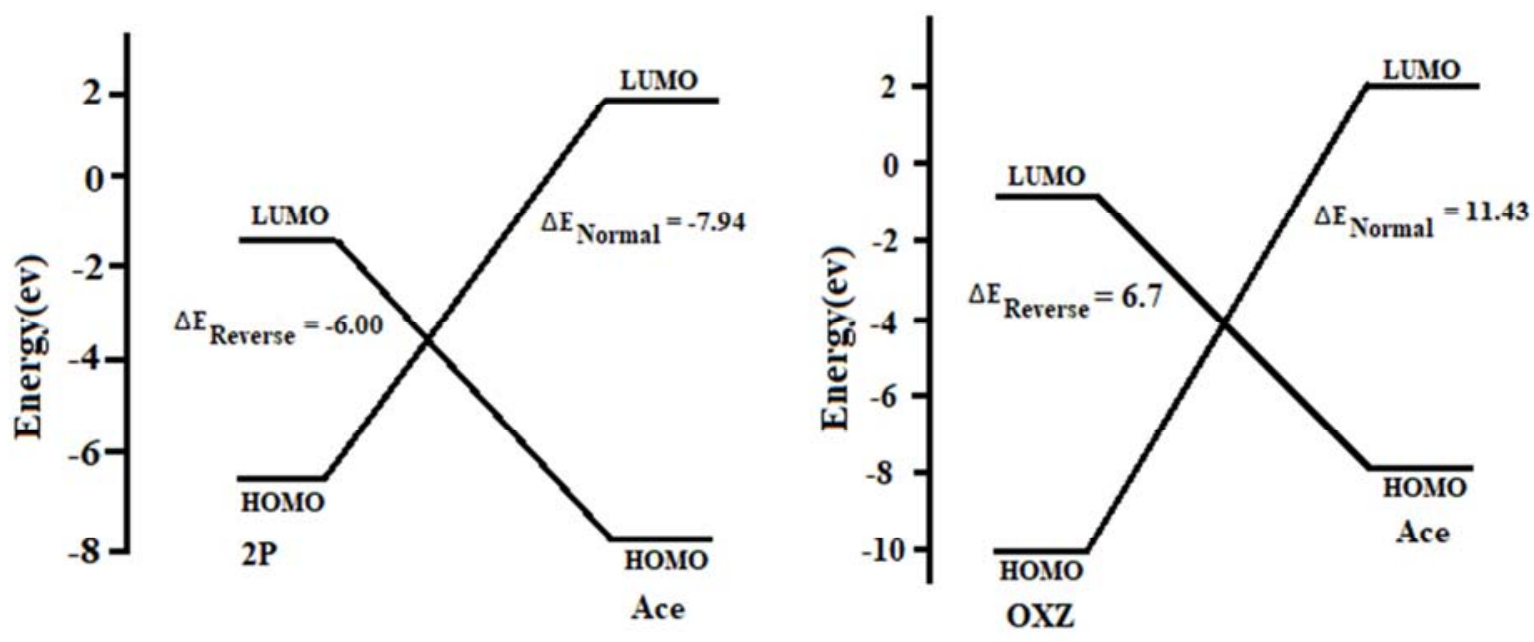

Figure 5. Frontier Orbital separation in diene and dienophile pairs.

Table 1. Lengths of forming and cleaving bonds during cycloaddition and cleaving during cycloreversion, asynchronicity (a). Quantum of charge transferred during cycloaddition of simple and substituted pyrones with acetylene.

\begin{tabular}{|c|c|c|c|c|c|c|c|}
\hline \multirow{2}{*}{ System } & \multicolumn{4}{|c|}{ Cycloaddition } & \multicolumn{3}{|c|}{ Cycloreversion } \\
\hline & C6-C7 & C3-C8 & $\% \alpha$ & $\mathbf{Q}_{\text {ст }}$ (dienophile to diene) & C6-O1 & O2-C3 & $\% \alpha$ \\
\hline $2 \mathrm{P}$ & 2.15 & 2.33 & 4.0 & 0.024 & 1.93 & 1.74 & 4.6 \\
\hline $3 \mathrm{~F} 2 \mathrm{P}$ & 2.16 & 2.30 & 3.1 & 0.018 & 1.90 & 1.78 & 3.3 \\
\hline $3 \mathrm{Cl} 2 \mathrm{P}$ & 2.11 & 2.36 & 5.6 & 0.052 & 1.88 & 1.83 & 1.3 \\
\hline $3 \mathrm{Br} 2 \mathrm{P}$ & 2.12 & 2.34 & 4.8 & 0.039 & 1.89 & 1.83 & 2.0 \\
\hline $4 \mathrm{~F} 2 \mathrm{P}$ & 2.12 & 2.34 & 4.9 & 0.038 & 1.93 & 1.75 & 4.9 \\
\hline $4 \mathrm{Cl} 2 \mathrm{P}$ & 2.16 & 2.32 & 3.6 & 0.043 & 1.93 & 1.76 & 4.6 \\
\hline $4 \mathrm{Br} 2 \mathrm{P}$ & 2.16 & 2.32 & 3.6 & 0.043 & 1.93 & 1.73 & 5.5 \\
\hline $5 \mathrm{~F} 2 \mathrm{P}$ & 2.15 & 2.37 & 4.9 & 0.030 & 1.92 & 1.75 & 4.6 \\
\hline $5 \mathrm{Cl} 2 \mathrm{P}$ & 2.13 & 2.38 & 5.5 & 0.048 & 1.92 & 1.77 & 4.1 \\
\hline $5 \mathrm{Br} 2 \mathrm{P}$ & 2.12 & 2.39 & 6.0 & 0.050 & 1.92 & 1.77 & 4.1 \\
\hline $6 \mathrm{~F} 2 \mathrm{P}$ & 2.12 & 2.34 & 4.9 & 0.019 & 1.92 & 1.74 & 4.9 \\
\hline $6 \mathrm{Cl} 2 \mathrm{P}$ & 2.17 & 2.28 & 2.5 & 0.050 & 1.92 & 1.72 & 5.5 \\
\hline $6 \mathrm{Br} 2 \mathrm{P}$ & 2.16 & 2.29 & 2.9 & 0.052 & 1.92 & 1.72 & 5.5 \\
\hline
\end{tabular}

$\% \alpha=\mid(\Delta \mathrm{r} /(\mathrm{r} 1+\mathrm{r} 2) \mid \mathrm{x} 100$ where $\mathrm{r} 1 \& \mathrm{r} 2$ are the newly forming or cleaving bonds in the TSs

Table 2. Thermochemical activation and reaction parameters for the cycloaddition and cycloreversion of $2 P$, halosubstituted $2 P$ and OXZ with Ace. (Free energy of enthalpy is in $\mathrm{kcal} \mathrm{mol}^{-1}$ ).

\begin{tabular}{|c|c|c|c|c|c|c|c|c|c|c|}
\hline \multicolumn{6}{|c|}{ Cycloaddition } & \multicolumn{5}{|c|}{ Cycloreversion } \\
\hline \multirow{2}{*}{ System } & \multicolumn{3}{|c|}{ Activation parameters } & \multicolumn{2}{|c|}{ Reaction parameters } & \multicolumn{3}{|c|}{ Activation parameters } & \multicolumn{2}{|c|}{ Reaction parameters } \\
\hline & $\Delta \mathbf{G}^{\ddagger}$ & $\Delta \mathbf{H}^{\ddagger}$ & $\Delta \mathbf{S}^{\ddagger}$ & $\Delta \mathbf{H}_{\mathrm{r}}$ & $\Delta \mathbf{G}_{\mathbf{r}}$ & $\Delta \mathbf{G}^{\ddagger}$ & $\Delta \mathbf{H}^{\ddagger}$ & $\Delta \mathbf{S}^{\ddagger}$ & $\Delta \mathbf{H}_{\mathrm{r}}$ & $\Delta \mathbf{G}_{\mathrm{r}}$ \\
\hline $2 \mathrm{P}$ & 36.84 & 25.35 & -38.56 & -29.38 & -16.36 & 11.97 & 12.14 & 0.57 & -54.34 & -66.75 \\
\hline $3 \mathrm{~F} 2 \mathrm{P}$ & 34.81 & 18.68 & -54.13 & -31.17 & -17.98 & 11.13 & 11.47 & 1.14 & -57.65 & -70.23 \\
\hline $3 \mathrm{Cl} 2 \mathrm{P}$ & 36.1 & 24.47 & -39.02 & -28.62 & -15.42 & 11.5 & 11.89 & 1.31 & -58.79 & -71.42 \\
\hline $3 \mathrm{Br} 2 \mathrm{P}$ & 35.39 & 23.71 & -39.19 & -29.64 & -16.45 & 11.69 & 12.08 & 1.31 & -57.31 & -69.94 \\
\hline $4 \mathrm{~F} 2 \mathrm{P}$ & 38.12 & 24.24 & -46.58 & -29.2 & -13.85 & 10.66 & 10.99 & 1.1 & -56.72 & -69.06 \\
\hline $4 \mathrm{Cl} 2 \mathrm{P}$ & 36.75 & 25.28 & -38.49 & -29.19 & -16.23 & 11.83 & 12.16 & 1.1 & -55.45 & -67.79 \\
\hline $4 \mathrm{Br} 2 \mathrm{P}$ & 36.59 & 25.17 & -38.32 & -29.33 & -16.4 & 11.79 & 12.12 & 1.11 & -55.32 & -67.63 \\
\hline $5 \mathrm{~F} 2 \mathrm{P}$ & 43.17 & 31.79 & -38.19 & -24.22 & -11.25 & 12.59 & 12.92 & 1.1 & -57.49 & -69.83 \\
\hline $5 \mathrm{Cl} 2 \mathrm{P}$ & 37.28 & 25.88 & -38.26 & -29.87 & -16.88 & 12.89 & 13.25 & 1.21 & -55.53 & -67.87 \\
\hline $5 \mathrm{Br} 2 \mathrm{P}$ & 36.24 & 24.86 & -38.19 & -30.52 & -17.54 & 12.81 & 13.17 & 1.21 & -55.37 & -67.37 \\
\hline $6 \mathrm{~F} 2 \mathrm{P}$ & 36.72 & 25.02 & -39.26 & -29.67 & -16.43 & 10.75 & 11.12 & 1.24 & -52.05 & -64.65 \\
\hline $6 \mathrm{Cl} 2 \mathrm{P}$ & 37.91 & 26.15 & -39.46 & -28.47 & -15.22 & 10.39 & 10.7 & 1.04 & -56.93 & -69.53 \\
\hline $6 \mathrm{Br} 2 \mathrm{P}$ & 36.99 & 25.22 & -39.5 & -29.4 & -16.14 & 10.55 & 10.84 & 0.97 & -56.49 & -69.07 \\
\hline $\mathrm{OXZ}$ & 30.99 & 19.55 & -38.39 & -38.98 & -25.85 & 14.5 & 14.95 & 1.44 & -64.93 & -62.5 \\
\hline
\end{tabular}

The values in the parenthesis are stand for the HCN elimination pathway 


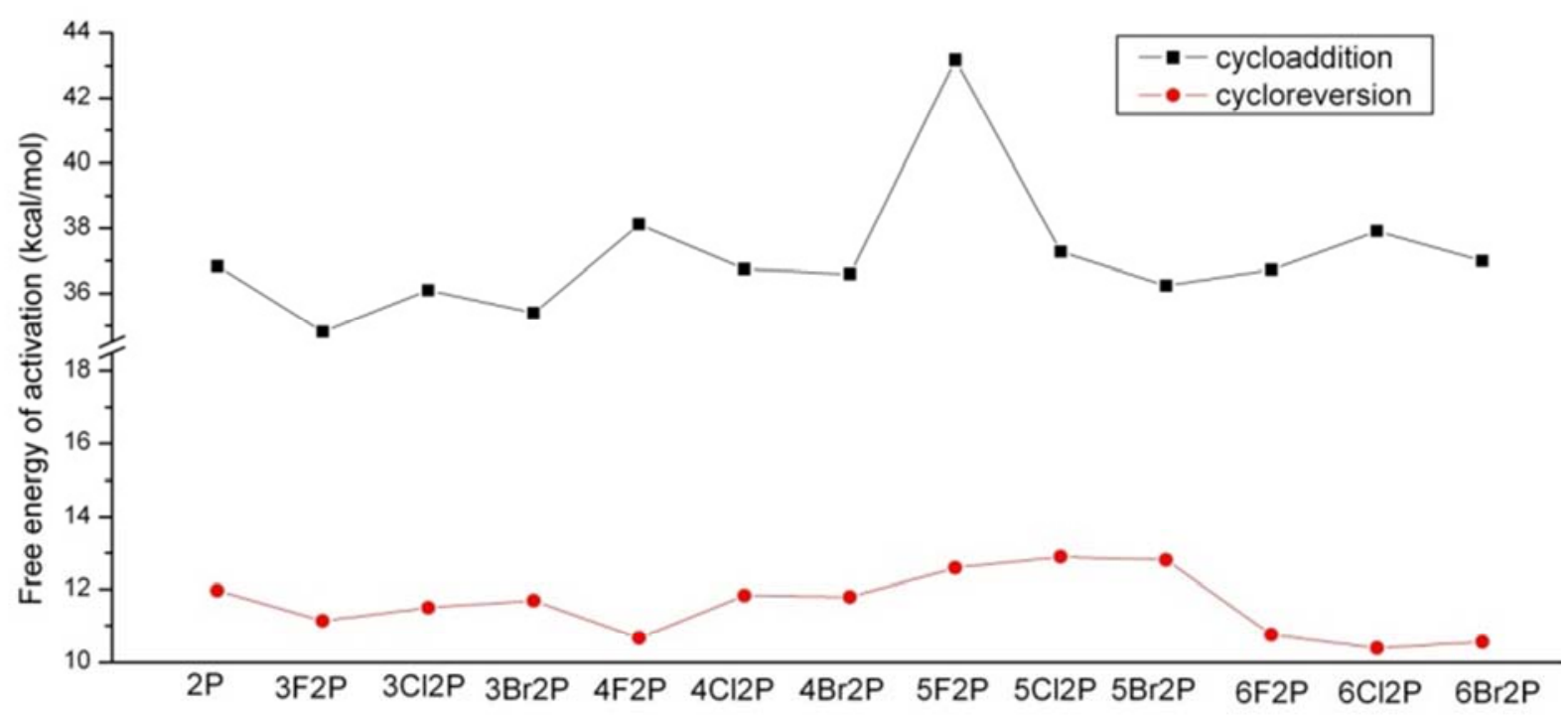

Figure 6. Variation of $\Delta G^{t}$ of cycloaddition and cyloreversion of Ace with various halopyrones as dienophiles.

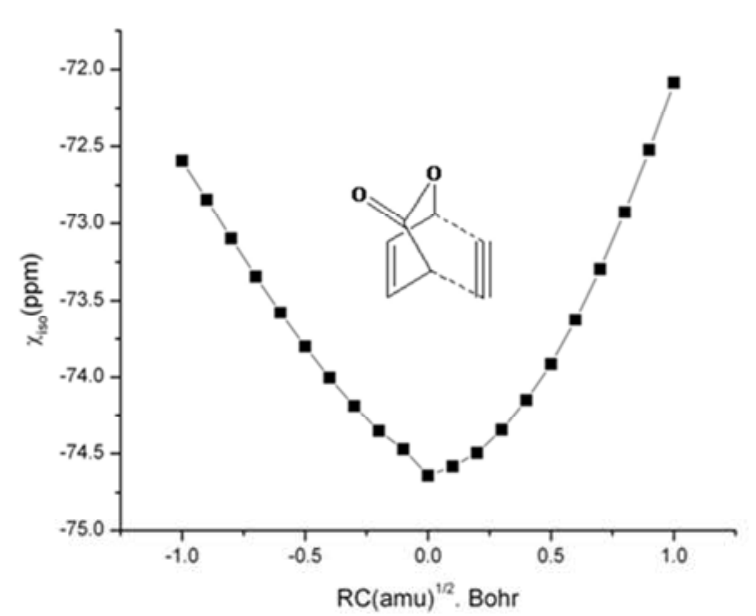

a

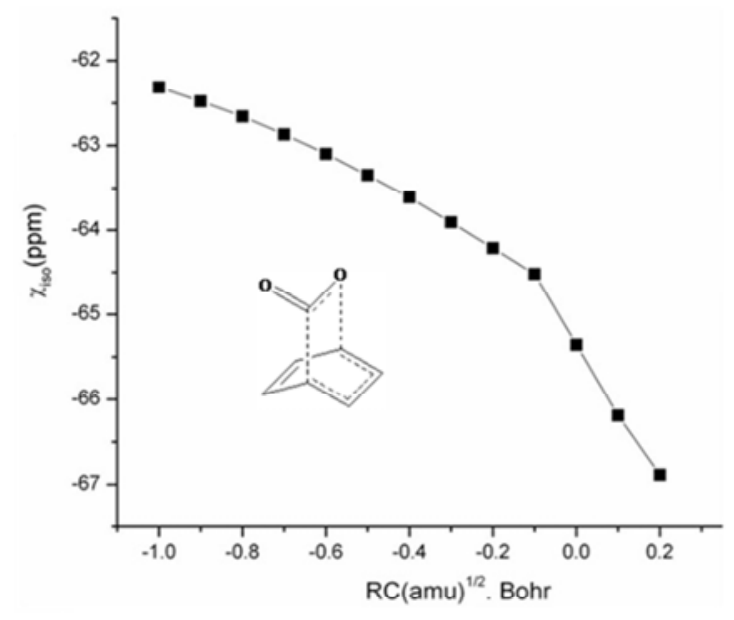

C

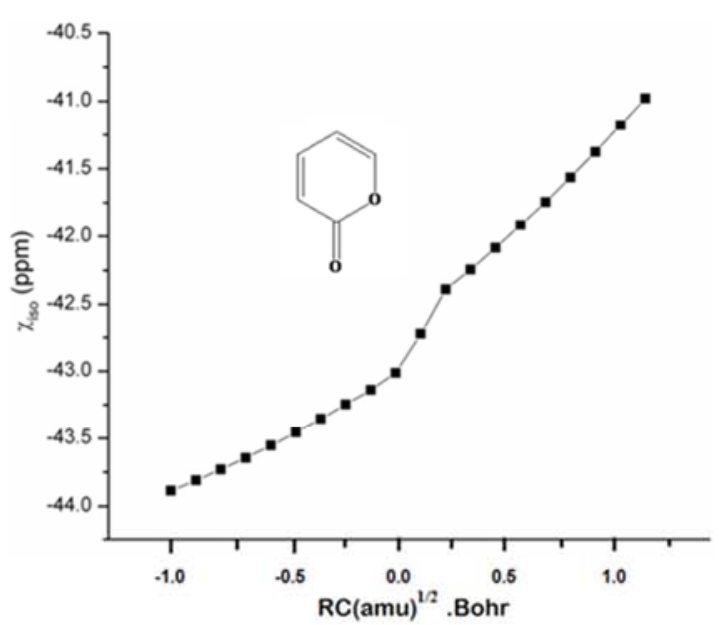

b

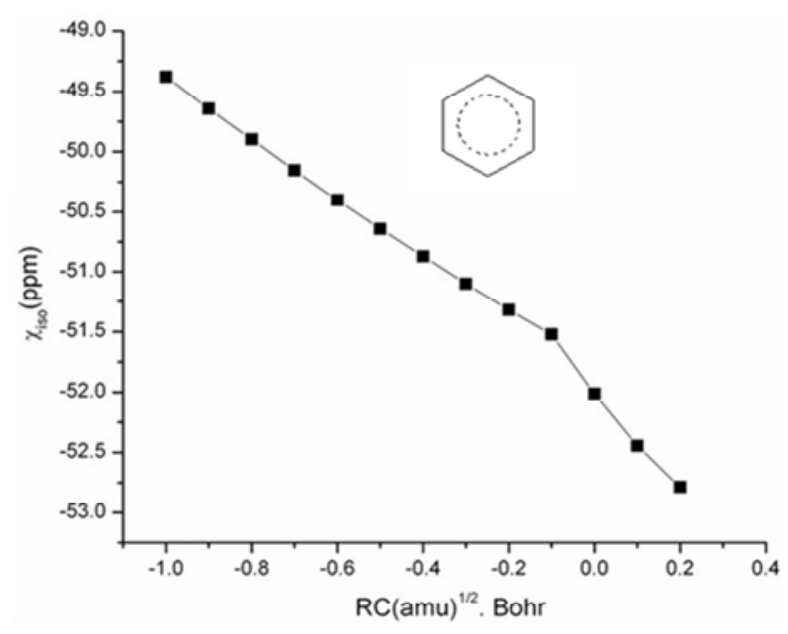

d

Figure 7. Variation of Magnetic susceptibility along the reaction coordinate of (a) TS1 (b) Pyrone ring of TS1 (c) TS2 (d) Benzene ring of TS2in $2 P$-Ace reaction. 


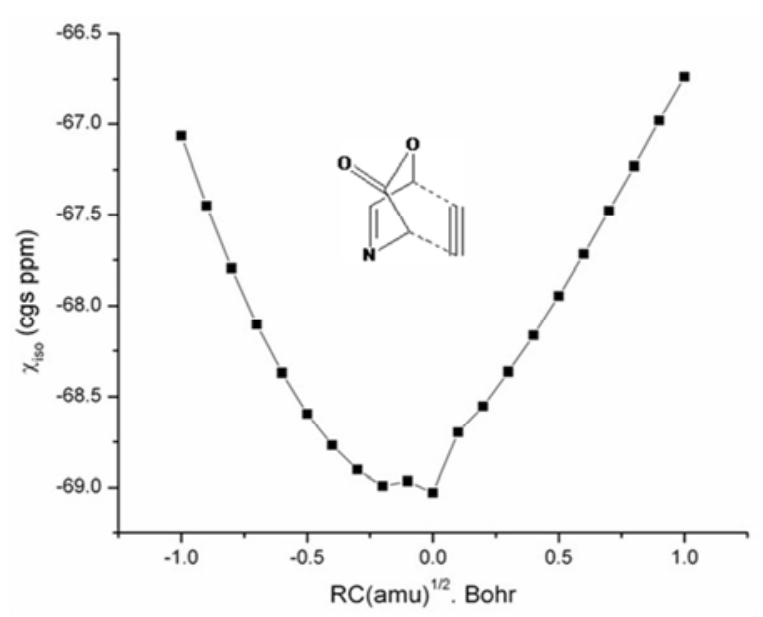

a

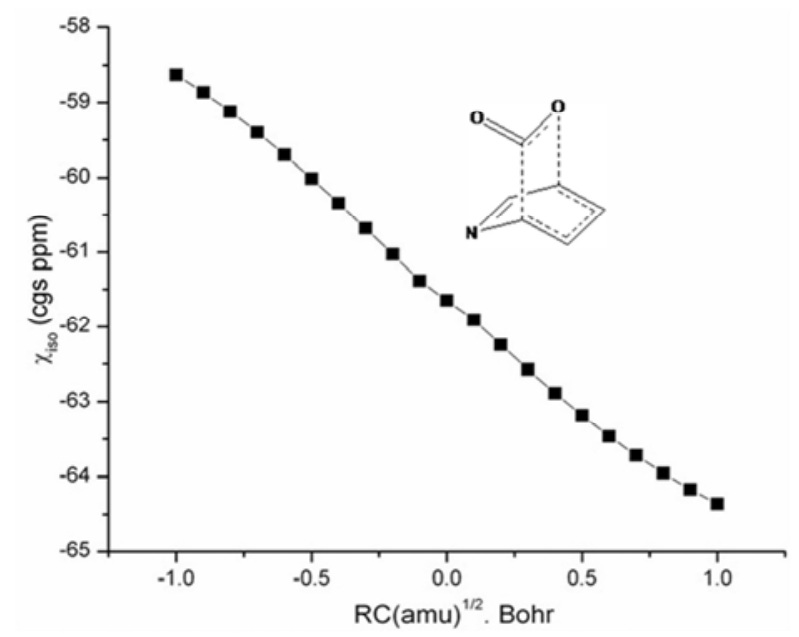

c

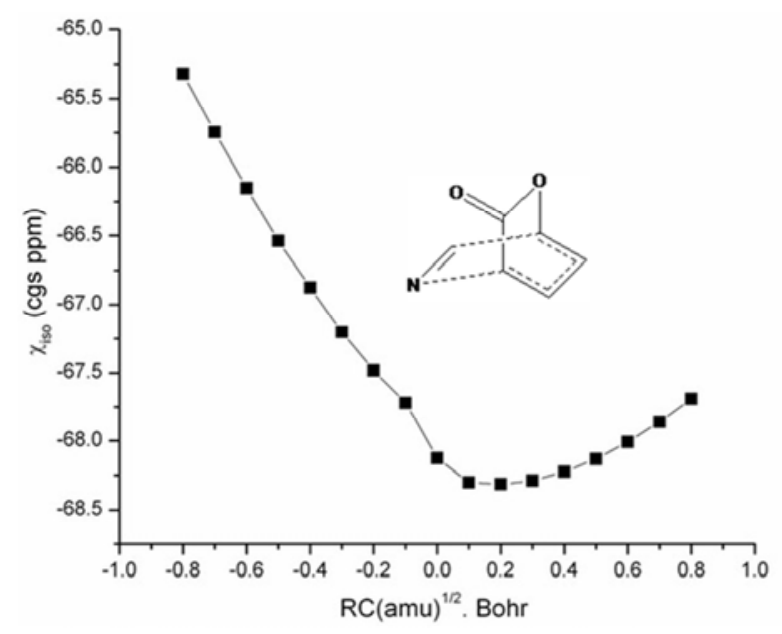

e

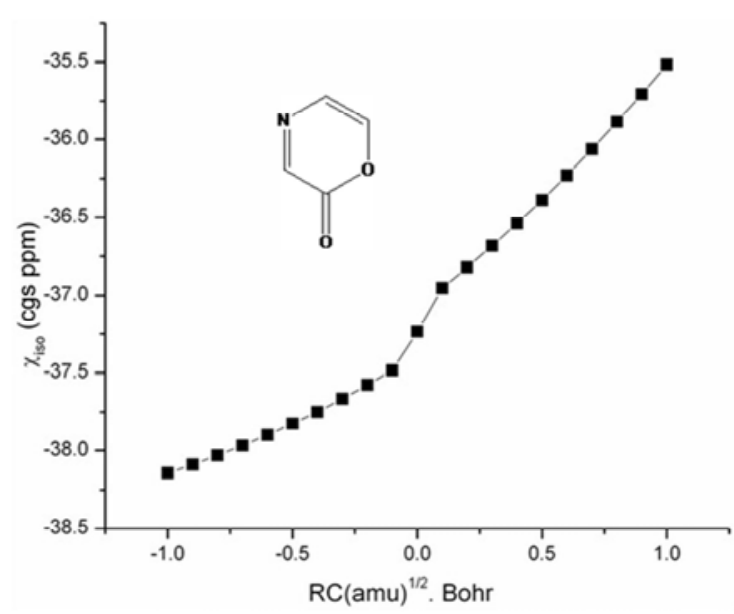

b

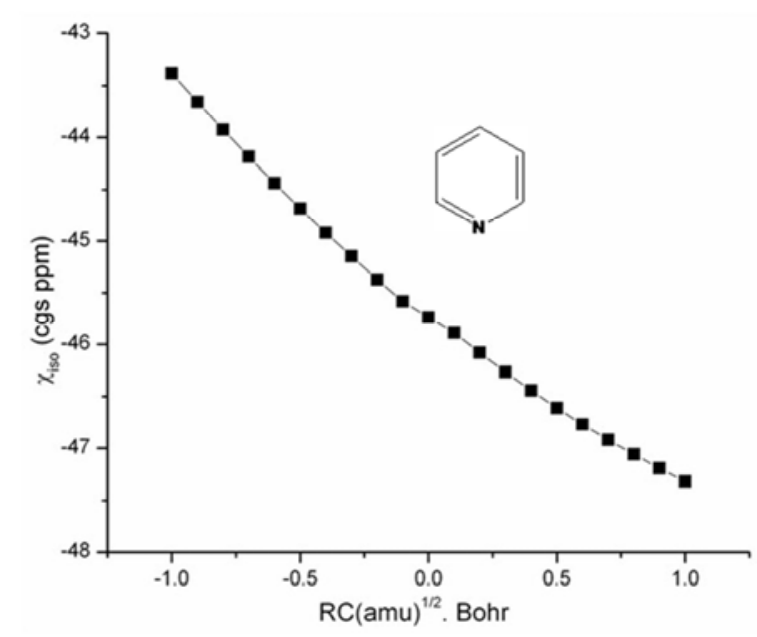

d

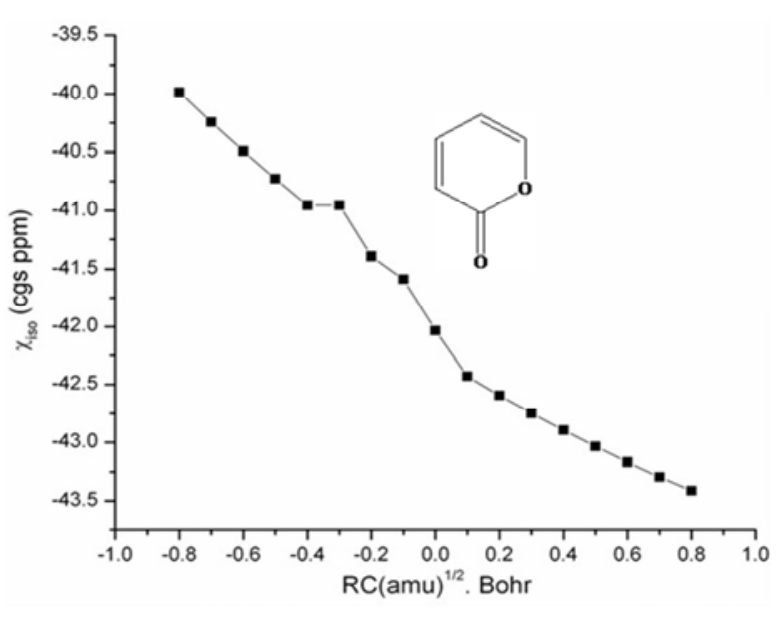

f

Figure 8. Variation of Magnetic susceptibility along the reaction coordinate of (a) TS3 (b) Pyrone ring of TS3 (c) TS4 (d) Pyrone ring of TS4 (e) TS5 (f) Pyrone ring of TS5 in OXZ-Ace reaction.

B. Aromaticity along the CA-CR pathway

During the first step the 2-pyrone loses its partial aromatic character and forms the cycloadduct. Two electronic phenomena are happening viz., loss of partial aromaticity in 
the pyrone ring and gain in the aromaticity in the pericyclic ring along the reaction coordinate. Now the $\chi_{\text {iso }}$ of the whole system and of the reacting 2-pyrone fragment as a function of reaction coordinate have been monitored and presented in the Figure 6 (a) and (b) respectively. The nature of change in $\chi_{\text {iso }}$ along IRC, as shown in Figure 7 (a), reveals that the aromatic gain in the pericyclic ring is dominant and not have been upset by any loss of aromaticity in the reactant as given in Figure 7 (b). A completely opposite phenomenon has been observed in the second step. The reactant system shows continuous increase $m$ negative $\chi_{\text {iso }}$ and this trend parallels the trend shown by the product fragment along the IRC and as shown in Figure 7 (c) and (d). A sweeping change in aromatic game by the formation of benzene ring as the product offsets the changes in $\chi_{\text {iso }}$ in the pencyclic ring. This case is similar to that reported by Manoharan et al., [30] wherein he demonstrates that the usual $6 \mathrm{e}^{-}$cyclic $(\sigma, \pi)$ delocalization of the pericyclic TS will be accompanied by the partial delocalization of the peripheral ring of o-quinodimethane (diene). On account of this aromatic gain, the cycloaddition between o-quinodimethane and ethylene occurs with relatively low barrier than the proto type butadiene and ethylene addition. In the present case cycloreversion is accelerated on account of aromaticity developed in the newly forming ring.

\section{OXZ-Ace Reaction}

OXZ-Ace reaction resembles $2 \mathrm{P}$-Ace reaction in that it forms a bicyclic lactone first and then the lactone decomposes to give the final product. The above reactions differ in that the latter has two paths to cyclorevert; (i) $\mathrm{CO}_{2}$ elimination (ii) $\mathrm{HCN}$ elimination. The trend in aromaticity changes as observed through changes in $\chi_{\text {iso }}$ are presented in Figures 7 and 8 . They are quite similar for both the reactions as far as cycloaddition and $\mathrm{CO}_{2}$ elimination steps are concerned. Two changes can be noted in OXZ-Ace reaction, (i) TS3 is less aromatic than TSl as reflected by lower $\chi_{\text {iso }}$ values andthis is due to the presence of nitrogen atom in the ring. (ii) The change in aromaticity in $\mathrm{HCN}$ elimination path, during cycloreversion is dominated by the aromaticity of the pericyclic ring in TS5, as the final product formed is 2-pyrone that is only partially aromatic. One can observe this from the Figure 5 (c) and (d). This clearly explains the reluctance of the bicyclic lactone adduct (A2) to choose the nitrile elimination path where there is lesser aromaticity gain than in the alternative $\mathrm{CO}_{2}$ elimination path.

\section{Conclusion}

Tandem cycloaddition-cycloreversion of 2-pyrone and its aza analogue, 1,4-oxazinone with acetylene follows concerted mechanism with asynchronous transition states. 2P-Ace cycloadduct rapidly cycloreverts due to the aromatic enhancement. In OXZ-Ace adduct, two extrusible fragments (viz., $\mathrm{CO}_{2} \& \mathrm{HCN}$ ) compete and the barriers indicate that $\mathrm{CO}_{2}$ extrusion is facile due to the excellent gain in aromaticity during the process.

\section{References}

[1] Neunhoeffer, H. and Werner, G. (1974). Cycloadditionen mit Azabenzolen, VII 1) Reaktion von pyrimidinen mit $\mathrm{N}, \mathrm{N}$ diäthyl-1-propinylamin. Justus Liebigs Annalen Chemie, 8, 1190. doi.org/10.1002/jlac.197419740803.

[2] Grigg, R., Hayes and Jackson, J. L. (1969). Thermal elimination reactions of nitrogen and sulphur heterocycles. Journal of the Chemical Society, 1167. doi.org/10.1039/C29690001167.

[3] Diels, O.; Alder, K. (1931). Synthesen in der hydroaromatischen Reihe, XIII. Justus Liebigs Annalen der Chemie. 490, 257. doi: 10.1002/jlac.19314900111.

[4] Afarinkia, K., Nelson, T. D., Vinader, M. V. and Posner, G. H. (1992), Diels-Alder cycloadditions of 2-pyrones and 2pyridones. Tetrahedron., 48, 9111. doi.org/10.1016/S00404020(01)85607-6.

[5] Woodward, B. T.; Posner, G. H. Adv. Cycloaddit. 1999, 5, 47. 5. a) Damien F. P. Crepin, Joseph P. A. Harrity, Julong Jiang, Anthony J. H. M. Meijer, Anne-Chloé M. A. Nassoy, and Piotr Raubo. (2014), A mechanic study of the Lewis basedirected cycloaddition of 2-pyrones and alkynylboranes. Journal of the American Chemical Society. 136, 24, 8642. doi: $10.1021 / \mathrm{ja} 501805 \mathrm{r}$.

[6] Posner, G. H., Wettlaufer, D. G., (1986), Highly stereocontrolled synthesis of some trioxygenated cyclohexenes: an asymmetric total synthesis of (-)-methyl triacetyl-4-epishikimate. Journal of American Chemical Society. 108, 23, 7373. doi.org/10.1021/ja00283a036.

[7] Posner, G. H., Haces, A., Harrison, W. and Kinter, C. M., (1987), Highly stereocontrolled synthesis of some polyfunctionalized cyclohexenes. A short formal total synthesis of (.+-.)- chorismic acid. The Journal of Organic Chemistry, 52, 22, 4836. doi. 10.1021/jo00231a002.

[8] Posner, G. H.; Kinter, C. M. (1990) Asymmetric total synthesis of an A-ring precursor to hormonally active 1. alpha., 25-dihydroxyvitamin D3 J. Org. Chem. 55, 3967. https://doi.org/10.1021/jo00300a001.

[9] Posner, G. H. and Nelson, T. D. (1990), Stereocontrolled synthesis of highly functionalized cyclohexenes. A short synthesis of a chorismic acid precursor. Tetrahedran, 46, 4573. doi.org/10.1016/S0040-4020(01)85582-4.

[10] Jung, M. E.; Head, D. B. Bull. Soc. Chim. Fr. 1990, 127, 830.

[11] Marko, I. E., Seres, P., Swarbnck, T. M., Staton, I and Adams, H. (1992), Tandem pericyclic reactions. The first X-ray structure of an initial pyrone-olefin adduct and an easy, stereocontrolled, entry into polyoxygenated cyclohexanes. Tetrahedron Letters, 1992, 33, 5649. doi.org/10.1016/S00404039(00)61170-X.

[12] Afarinkia, K. and Mahmood, F. (1999), A novel and concise synthesis of 2-epi-validamine, Tetrahedron, 1999, 55, 3129. doi.org/10.1016/S0040-4020(99)00071-X.

[13] Ireland, R. E., Anderson, R. C, Badoud, R., Fitzsimmons, B. J., McGarvey, T. J. and Thaisnvongs, S. (1983), The total synthesis of ionophore antibiotics. A convergent synthesis of lasalocid A (X537A), Journal of the American Chemical Society, 105, 1988. doi: 10.1021/ja00345a055. 
[14] Boger, D. L. and Brotherton, C. E. (1984), Total synthesis of azafluoranthene alkaloids: rufescine and imeluteine, The Journal of Organic Chemistry, 49, 4050. doi: 10.1021/jo00195a035.

[15] Ahmed, S. A., Bardshin, E. and Simpson, T. J. (1987), A convenient synthesis of isotopically labeled anthraquinones, chrysophanol, islandicin and emodin. Incorporation of [methyl- ${ }^{2} \mathrm{H}_{3}$ ] chrysophanol into tajixanthone in Aspergillus variecolor, Journal of the Chemical Society, Chemical Communications, 12, 883. doi.org/10.1039/C39870000883.

[16] Boger, D. L. and Mullican, M. D. (1984), Inverse electron demand Diels-Alder reactions of 3-carbomethoxy-2-pyrones. Controlled introduction of oxygenated aromatics: benzene, phenol, catechol, resorcinol and pyrogallol annulation. Regiospecific total synthesis of sendaverine and a preparation of 6,7-benzomorphanes, Journal of Organic Chemistry, 49, 4033. doi.org/10.1021/jo00195a033.

[17] Yamaguchi, R., Otsuji, A., Utimoto, K. and Kozima, S. (1992) 1,2-Addition of allyl and 2-oxo-2H-pyran-6-ylcarbonyl groups to cyclic $\mathrm{C}=\mathrm{N}$ double bonds by means of organotin reagent for alkaloids synthesis; A facile synthesis of 8-oxoprotoberberine and norketoyobirine (Demethoxycarbonyloxogambirtannine), Bulletin of the Chemical Society of Japan. 65, 298. doi.org/10.1246/bcsj.65.298.

[18] a) Afarinkia, K., Vmader, V., Nelson, T. D. and Posner, G. H, (1992), Diels-Alder cycloadditions of 2-pyrones and 2pyridones, Tetrahedron, 48, 9111. doi.org/10.1016/S00404020(01)85607-6 b) Kvita, V, Fischer, W. Chimia. 1993, 47, 3. c) Kalinin, V. N, Shilova, O. S, Russ. chem Rev. 1994, 63, 661. d) Woodward, B. T.; Posner, G. H, Recerit Advaixces in DielsAlder Cycloadditions of 2-Pyrones. Advances in Cydoaddition; JAI Press: Greenwich, 1999; Vol. 5. P47.

[19] Frisch, M. J et al, Gaussian 98 (Revision A. 9), Gaussian, Inc. Pittsburgh, PA, 1998.

[20] Becke, A. D. (1993), Density-functional thermochemistry.III. The role of exact exchange. The Journal of Chemical Physics, 98, 5648. doi.org/10.1063/1.464913.

[21] Lee, C., Yang, W. and Parr, R. G. (1988), Development of the
Colle-Salvetti correlation-energy formula into a functional of the electron density. Physical Review B, 37, 785. doi.org/10.1103/PhysRevB.37.785.

[22] Keith, T. A.; Bader, R. F. W. (1993) Calculation of magnetic response properties using a continuous set of gauge transformations Chem. Phys. Lett., 220, 223, https://doi.org/10.1016/0009-2614(93)89127-4.

[23] Keith, T. A. and Bader, R. F. W. (1992), Calculation of magnetic response properties using atoms in molecules. Chemical Physics Letters, 194, 1. doi.org/10.1016/00092614(92)85733-Q.

[24] Cheeseman, J. R., Frisch, M. J., Trucks, G. W. and Keith, T. A. (1996), A comparison of models for calculating nuclear magnetic resonance shielding tensors, The Journal of Chemical Physic, 104, 5497. doi.org/10.1063/1.471789.

[25] Foster, J. P. and Weinhold, F. (1980), Natural hybrid orbitals, Journal of American Chemical Society, 102, 7211. doi.org/10.1021/ja00544a007.

[26] Reed, A. D., Curtiss, L. A. and Weinhold, F, (1988), Intermolecular interactions from a natural bond orbital, donoracceptor viewpoint, Chemical Reviews, 88, 899. doi.org/10.1021/cr00088a005.

[27] Glendening, E. D.; Reed, A E; Carpenter, J. E.; Weinhold, F, NBO 3.1 Program Manual, 1988.

[28] Froese, R. D. J.; Coxon, J. M.; West, S. C; Morokuma, K. (1997) Theoretical Studies of Diels-Alder Reactions of Acetylenic Compounds, J. Org. Chem. 1997, 62, 6991. https://doi.org/10.1021/jo970811u.

[29] Manoharan, M.; Venuvanalingam, P (1998) Gain or loss of aromaticity in Diels-Alder transition states and adducts: a theoretical investigation/. Phys. Org. Chem., 11, 133. https://doi.org/10.1002/(SICI)1099-

1395(199802)11:2<133::AID-POC981>3.0.CO;2-R.

[30] Manoharan, M.; De Proft, F.; Geerlings, P. Aromaticity Interplay between Quinodimethanes and $\mathrm{C}_{60}$ in Diels-Alder Reactions: Insights from a Theoretical Study J. Org. Chem. 2000, 65, 6132 https://doi.org/10.1021/jo970811u. 